\title{
A Rare Case of Nasal Glial Heterotopia Presenting as Sphenochoanal Polyp*
}

\author{
Pavol Surda, Jonathan Hobson \\ Ear, Nose and Throat Department, Warrington and Halton Hospitals, Warrington, UK \\ Email: pavol.surda@gmail.com
}

Received 6 February 2015; accepted 24 February 2015; published 28 February 2015

Copyright (C) 2015 by authors and Scientific Research Publishing Inc.

This work is licensed under the Creative Commons Attribution International License (CC BY). http://creativecommons.org/licenses/by/4.0/

(c) (i) Open Access

\begin{abstract}
Objective: This paper reports a rare case of nasal glial heterotopia presenting as sphenochoanal polyp. So far, literature has revealed only few cases. Case Report: A 55-year-old woman presented with a 2-month history of left sided nasal obstruction. Rigid endoscopy showed greyish left nasal polyp and anterior discharge. Subsequently, CT scan of the sinuses revealed sphenochoanal polyp filling the left nasal cavity, without signs of expansion, or destruction and no obvious connection with intracranial tissue. Mass was removed endoscopically and histology confirmed glial nature of the mass. Conclusion: Any mass arising from sphenoid sinus should be carefully evaluated on CT scan for existence of fibrous stalk, or connection with brain tissue and needs to be considered in the differential diagnosis of the sphenochoanal mass. Complete surgical excision is the treatment of choice, which is curative.
\end{abstract}

\section{Keywords}

Heterotopic Glial Heterotopia, Sphenoid Sinus, Nasal Cavity, Sphenochoanal Polyp

\section{Introduction}

Nasal Glial Heterotopias (NGH) are congenital tumours of the midline frontonasal space arising from a normal neurectodermal tissue entrapped during the closure of the anterior neuropore. NGH, or differentiated neural tissue outside the cranial vault is uncommon, and these anomalies most commonly occur in the nasal cavity [1] [2]. However, heterotopic brain tissue has also less commonly been reported to occur in other sites, such as the pharynx, lung, orbits, palate, tongue, cheek, lip, and neck [3]. The reported incidence is 1 in every 20,000 to 40,000 births. The most common congenital nasal masses are nasal dermal sinus cysts, nasal encephaloceles, and NGH. These masses appear to share a similar embryogenic origin. They occur when the neuroectodermal and ecto-

*The paper was presented as poster at the congress of European Rhinologic Society in Amsterdam 2015.

How to cite this paper: Surda, P. and Hobson, J. (2015) A Rare Case of Nasal Glial Heterotopia Presenting as Sphenochoanal Polyp. International Journal of Otolaryngology and Head \& Neck Surgery, 4, 77-80.

http://dx.doi.org/10.4236/ijohns.2015.42014 
dermal tissues fail to separate during the development of the nose. NGH might link the intracranial dura mater through the foramen cecum and evidence of this connection is observed in about $15 \%$ of histopathological studies and referred as a "fibrous stalk" [4].

The extranasal form (60\%) is superficially located, and expands into the subcutaneous space [4]. Intranasal NGH, the topic in this case report, account for $30 \%$ of all NGH seen at birth and are frequently revealed by respiratory distress in the early life. Majority of intranasal form involves the cribriform plate. NGH presenting as sphenochoanal mass are rare. Mixed form (10\%) associates both extranasal and intranasal extensions [5].

Histologically, they are composed of astrocytes and neuroglial fibers intermixed with a fibrovascular connective tissue stroma. Occasionally, rare neurons and/or ependymal cystic structures may be present as well. These cells were S-100 protein and glial fibrillary acid protein (GFAP) positive, confirming their glial nature [6].

Unilateral lesion occupying sphenoid sinus is uncommon. Etiology may be inflammatory (including chronic invasive fungal sinusitis), a benign neoplasm (e.g. inverted papilloma, hemangioma, angiofibroma), malignant neoplasm, congenital tumor (encephalocele), an internal carotid artery aneurysm, a pituitary adenoma or an ectopic pituitary [7].

CT and MR imaging are useful in the evaluation of masses involving the skull base. CT provides information about the adjacent osseous structures while MR imaging, because of its improved soft-tissue resolution, helps to characterize the soft-tissue abnormality. Angiofibromas and hemangiomas are vascular tumors that enhance avidly after contrast administration and may show an abundance of flow voids on MR images. Nasopharyngeal carcinoma involving sphenoid sinus will show replacement of fat in this location and, if extensive, may result in expansion of the sinus.

Complete surgical excision is the treatment of choice. In the early management of NG, bifrontal craniotomy has been recommended [5] [8]. Improvements in technology, surgical technique, and medical environment result in introducing a single staged endoscopic endonasal procedure in the treatment of NGH [9].

The objective of this paper is to raise awareness of this rare congenital tumour, which should take part in differential diagnosis of all unilateral solitary sphenoidal lesions.

\section{Case Report}

We report the case of 55-year-old woman with Turner's syndrome, who presented with left sided sphenochoanal polyp causing nasal obstruction over 2 months. There has been an associated mucoid discharge, but no epistaxis, facial pain and cranial nerves were intact. Physical examination revealed a greyish nasal polyp and anterior discharge. There was no history of hoarseness, dysphagia, dyspnea, fever, weight loss, or any systemic or local complaints. Besides Turner's syndrome, the patient experienced common childhood diseases, diabetes II type and hypertension. She was never hospitalized before due to these minor ailments nor had she undergone any kind of surgeries. There was no relevant past allergy or drug history. Family history was negative. The results of complete blood count, white blood cell count, serum biochemistry and chest X-ray were normal. CT scan of the sinuses revealed sphenochoanal polyp filling left nasal cavity, without signs of expansion, or destruction (Figure 1). The osteomeatal complex was normal.

Patient underwent endoscopic endonasal removal of the polyp. Under general anesthesia we first examined nasal cavity. We identified greyish nasal polyp in left middle meatus arising from sphenoid sinus. There were no signs of abnormal mass pulsatility. Polypectomy was then progressively achieved with help of microdebrider and meticulous bipolar haemostasis to keep the operative field free of bleeding. We firstly removed the nasal portion and subsequently opened sphenoid sinus and completely removed the rest of the polyp. A fibrous stalk wasn't identified and there was no perioperative CSF leak. The histology of this polyp was confirmed following immuno-staining as containing heterotopic glial tissue (Figure 2).

At the post-op review, patient mentioned one episode of clear fluid leaking from her left nostril, which made impression of CSF leak. On examination with 30 degree rigid nasendoscopy the sphenoidotomy was nice and clear, there was no obvious fluid leakage or pooling and no recurrence of her polyps. Postoperative CT scan revealed a defect in the inferomedial aspect of the left temporal fossa communicating with the left sphenoid sinus and positive beta-2 transferrin test. Subsequently, we referred patient for further surgical CSF leak management to ENT department in Crewe Hospital, which was successfully achieved. In the 10 months follow-up period patient remained disease free with no signs of CSF leak. 

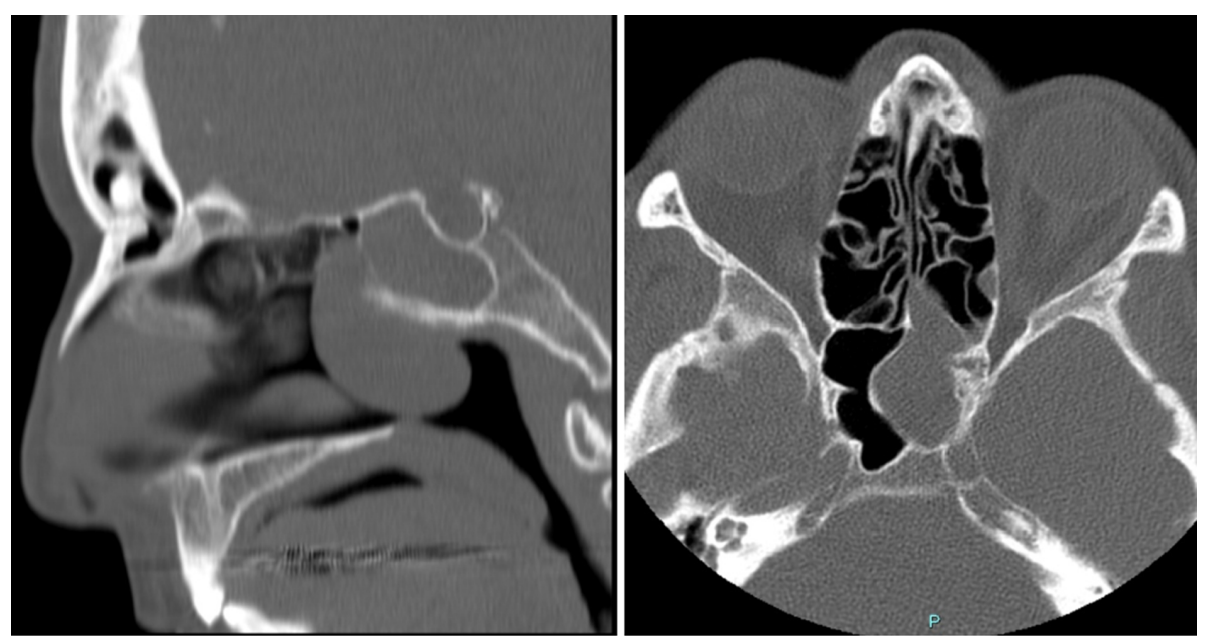

Figure 1. A 55-year-old woman with NGH in the sphenoid sinus: Axial and Sagittal CT scan shows a well-demarcated soft-tissue mass, which is extending into nasal cavity/post-nasal space.

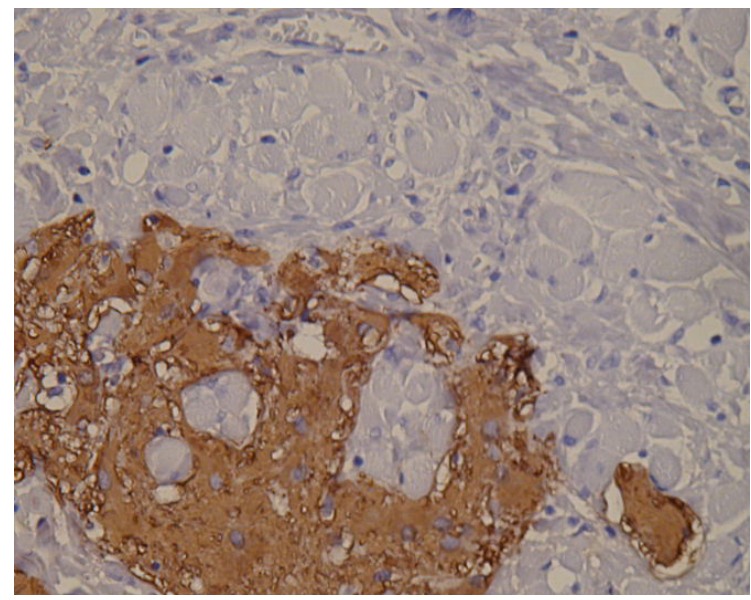

Figure 2. Immunohistochemical detection of glial fibrillary acidic protein.

\section{Discussion}

NGH of the spehonoidal sinus is a rare disease. The biggest challenge in the diagnostic process is the differentiation between encephalocele, which typically presents with marked connection between the mass and the intracranial tissue. However, NGH might link the intracranial dura mater through the foramen cecum. Evidence of this connection is observed in about $15 \%$ while still showing no communication with the brain parenchyma. Histopathological studies refer this connection as a "fibrous stalk". Clinically encephaloceles might present preoperatively with meningitis.

NGH are on T1-weighted images hypointense to isointense to gray matter. On T2-weighted images, T2 hyperintensity caused by gliosis is often observed within the mass. Dysplastic tissue does not typically enhance. The two entities may be distinguished from one another in that encephaloceles usually retain a visible connection with the brain [10] [11]. Rahbar et al., discussed this pathological finding, emphasizing difficulties in diagnosis, and concluded that gliomas should be distinguished from encephalocele only after clinicopathological correlation [12]. CT is useful for identifying small bone defects at the skull base, whereas MR imaging, with its multiplanar capabilities, is excellent for identifying communication with the adjacent brain.

Histologically, NGH and encephaloceles are characterized by varying proportions of neurons and glia, with three cases also showing gemistocytic astrocytes. There are varying degrees of fibrosis, frequently associated with inflammation (40\% of cases). Calcifications and ependymal-type cystic degeneration was also occasionally 
seen. Mason's trichrome stain combined with S-100 protein and glial fibrillary acidic protein can be most helpful in accentuating the neural tissue in the background fibrosis. Neuron specific enolase may be used if the other stains fail. It should be noted that there are no significant histologic differences between lesions with and without demonstrable CNS connection. Therefore, the accurate diagnosis of heterotopia versus encephalocele requires knowledge of the patient's radiographic and/or operative findings [6].

\section{Conclusions}

- Any mass arising from sphenoid sinus should be carefully evaluated on CT scan for existence of fibrous stalk, or connection with brain tissue.

- The diagnosis is usually uncertain until the final pathological report.

- Surgeons have to always perioperatively examine sphenoid sinus for any signs of CSF leak. CSF leak may be closed endoscopically in the first stage, or in the second stage in case of small defect.

- If the diagnosis of NGH was confirmed and there was no evident perioperative CSF leak, during the followup we should perform regular nasal endoscopy of sphenoid sinus.

- If CSF leak is not clearly present, we can measure beta-trace and beta-2 transferrin present in nasal fluid/ blood. If CSF leak is not clear, intrathecal fluorescein is very helpful.

- Incidence of perioperative CSF leak is 66\% [9].

\section{Conflict of Interest}

We have got no conflicts of interest to disclose.

\section{References}

[1] Ducic, Y. (1999) Nasal Gliomas. Journal of Otolaryngology, 28, 285-287.

[2] Uemura, T., Yoshikawa, A., Onizuka, T. and Hayashi, T. (1999) Heterotopic Nasopharyngeal Brain Tissue Associated with Cleft Palate. Cleft Palate-Craniofacial Journal, 36, 248-251. http://dx.doi.org/10.1597/1545-1569(1999)036<0248:HNBTAW>2.3.CO;2

[3] Hendrickson, M., Faye-Petersen, O. and Johnson, D.G. (1990) Cystic and Solid Heterotopic Brain in the Face and Neck: A Review and Report of an Unusual Case. Journal of Pediatric Surgery, 25, 766-768. http://dx.doi.org/10.1016/S0022-3468(05)80015-6

[4] Thomson, H.G., Al-Qattan, M.M. and Becker, L.E. (1995) Nasal Glioma: Is Dermis Involvement Significant? Annals of Plastic Surgery, 34, 168-172. http://dx.doi.org/10.1097/00000637-199502000-00009

[5] Walker Jr., E.A. and Resler, D.R. (1963) Nasal Glioma. Laryngoscope, 73, 93-107. http://dx.doi.org/10.1288/00005537-196301000-00008

[6] Penner, C.R. and Thompson, L. (2003) Nasal Glial Heterotopia: A Clinicopathologic and Immunophenotypic Analysis of 10 Cases with a Review of the Literature. Annals of Diagnostic Pathology, 7, 354-359. http://dx.doi.org/10.1016/j.anndiagpath.2003.09.010

[7] Sethi, D.S., Lau, D.P.C., Linchon, W.J. and Chong, V. (1998) Isolated Sphenoethmoid Recess Polyps. Journal of Laryngology Otology, 112, 660-663. http://dx.doi.org/10.1017/S0022215100141386

[8] Hughes, G.B., Sharpino, G., Hunt, W. and Tucker, H.M. (1980) Management of the Congenital Midline Nasal Mass: A Review. Head and Neck Surgery, 2, 222-233. http://dx.doi.org/10.1002/hed.2890020308

[9] Bonne, N.X., Zago, S., Hosana, G., Vinchon, M., Van den Abbeele, T. and Fayoux, P. (2012) Endonasal Endoscopic Approach for Removal of Intranasal Nasal Glial Heterotopias. Rhinology, 50, 211-217.

[10] Fuse, T., Aoyagi, M., Ota, N., Koike, Y. and Yuda, F. (1992) Heterotopic Brain Tissue of the Soft Palate. ORL Journal for Oto-Rhino-Laryngology and Its Related Specialties, 54, 54-56. http://dx.doi.org/10.1159/000276260

[11] Grossman, R.I. and Yousem, D. (1994) Neuroradiology: The Requisites. Mosby, St. Louis.

[12] Rahbar, R., Resto, V.A. and Robson, C.D. (2003) Nasal Glioma and Encephalocele: Diagnosis and Management. Laryngoscope, 113, 2069-2077. http://dx.doi.org/10.1097/00005537-200312000-00003 
Scientific Research Publishing (SCIRP) is one of the largest Open Access journal publishers. It is currently publishing more than 200 open access, online, peer-reviewed journals covering a wide range of academic disciplines. SCIRP serves the worldwide academic communities and contributes to the progress and application of science with its publication.

Other selected journals from SCIRP are listed as below. Submit your manuscript to us via either submit@scirp.org or Online Submission Portal.
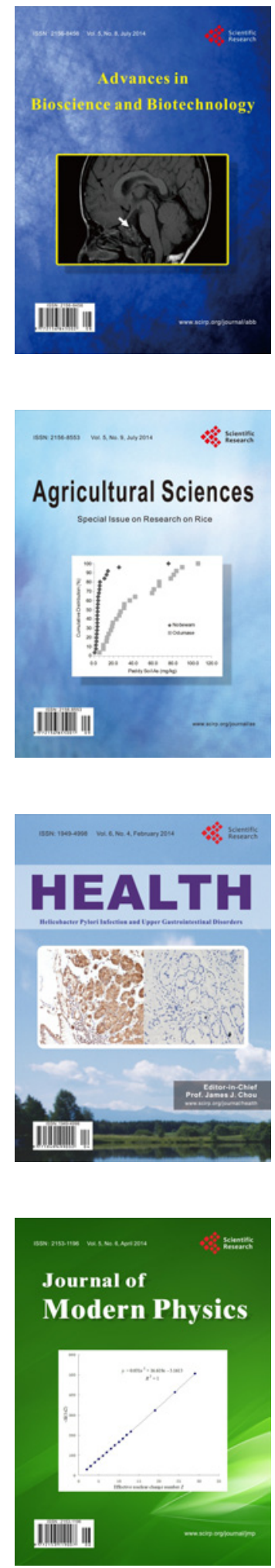
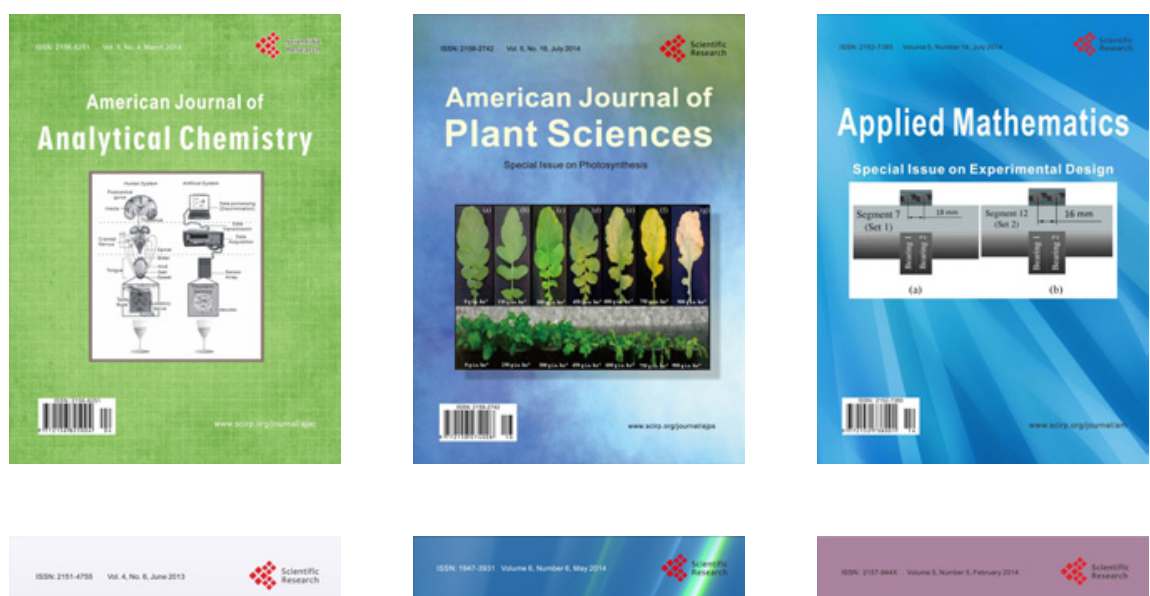

Creative Education
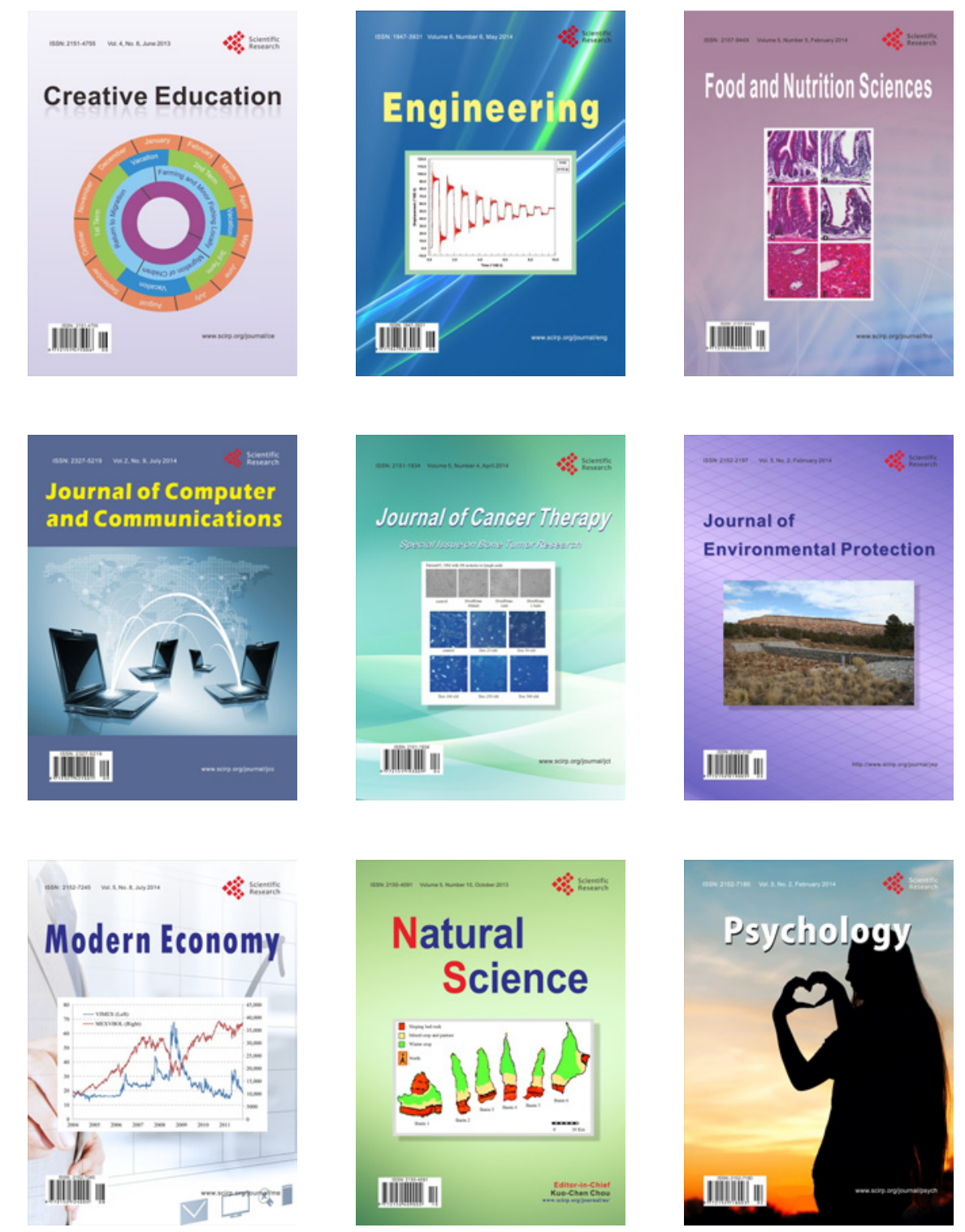